Por otra parte las especies del desierto $(R$. bagnoldii y $R$. ananuca) presentan floración primaveral y receso estival.

Bajo cultivo, las épocas de floración son similares a las del ambiente natural, sin embargo, $R$. bagnoldii y $R$. montana han florecido en distintas épocas del año.

Los estudios morfológicos mostraron que los tallos florales se disponen en línea en el plano medio del bulbo y emergen alternadamente. Todas las escamas son bases de hojas y cada 3 escamas hay un resto de tallo floral protegido por una escama semienvainadora. Se forman dos inflorescencias por año, las cuales emergen en la temporada siguiente. Los bulbos hijos se forman entre un resto de tallo floral y una escama semienvainadora

En la Universidad Austral de Chile se han logrado establecer los cariotipos de las especies en estudio, además, se han obtenido plantas tetraploides de $R$. splendens y $R$. montana, que se están cultivando en el invernadero de la E/E Panguilemo.

\section{CONCLUSIONES}

Las plantas presentan mejor comportamiento con temperaturas no extremas y un crecimiento más rápido con calor basal.

La fecha de floración no cambia al cultivar las plantas en invernadero, además $R$. montana y $R$. bagnoldii han mostrado distintas fechas de floración.

Los bulbos florales forman dos yemas florales por año

Existe una alta compatibilidad intraespecífica y con el género Phycella.

Agro Sur 35 (2): 67-69 2007

\title{
IDENTIFICACIÓN DE ENDOMICORRIZAS EN LA ORQUIIDEA NATIVA Gavilea araucana (PHIL.) CORREA
}

\section{IDENTIFICATION OF ENDOMYCORRHIZAE IN THE NATIVE ORCHID Gavilea araucana (PHIL.) CORREA}

\author{
Durán $^{1}$, C., Rivero ${ }^{2}$, M. y Seemann, P. ${ }^{1}$ \\ ${ }^{1}$ Instituto de Producción y Sanidad Vegetal, ${ }^{2}$ Instituto de Botánica. \\ Universidad Austral de Chile. Casilla 567, Valdivia, Chile. \\ E-mail: durancamila@gmail.com
}

\section{INTRODUCCIÓN}

Mediante prospecciones ya realizadas, se han encontrado en los alrededores de Valdivia, abundantes poblaciones naturales de orquídeas chilenas con gran potencial ornamental, pertenecientes a los géneros Chloraea, Codonorchis, Brachystele y Gavilea, las que producen flores de atractivos y variados colores. Para que estas poblaciones de orquídeas nativas no lleguen a estar amenazadas, es necesario realizar estudios en relación a la biología de este grupo de plantas, para recopilar información básica que sirva de fundamento para el manejo apropiado de éstas especies. En general, uno de los mayores problemas en el manejo y propagación de orquídeas radica en la escasa capacidad de germinación de sus semillas, debido a la deficiente reserva nutritiva para el embrión, por lo que dependen de un hongo micorrízico para su germinación en condiciones naturales. Para realizar un aprovechamiento sustentable de estas especies, considerando su conservación, es imprescindible realizar estudios micorrízicos que permitan implementar programas de propagación in situ. La asociación orquídea-micorriza ha sido poco investigada en Chile. Sin embargo, considerando la amplia ocurrencia de esta simbiosis en la familia Orchidaceae, y la importancia que ésta tiene 
sobre el establecimiento y crecimiento de las plantas, se plantea que Gavilea araucana debiera ser una especie hospedante de al menos un tipo de hongo endomicorrízico asociado a ella. El objetivo general de este estudio es determinar y caracterizar el o los tipos de hongos endomicorrízicos asociados a la raíz de la orquídea terrestre Gavilea araucana.

\section{MATERIALES Y MÉTODOS}

Raíces maduras de plantas de Gavilea araucana colectadas cerca de la ciudad de Valdivia, fueron desinfectadas para realizar la tinción de micorrizas, según el protocolo de Steubing et al., 2002. Se realizaron cortes histológicos de las raíces teñidas, los cuales se observaron bajo el microscopio óptico, para reconocer la asociación micorrízica.

Para determinar la presencia estacional de pelotones en las raíces, se realizaron secciones en raíces de 4 ejemplares de G. araucana . Dos raíces de cada ejemplar en otoño, dos raíces en invierno, dos en primavera y dos en verano, fueron seccionadas para observar la presencia de pelotones compactos bajo la lupa estereoscópica, utilizando el signo (+) cuando hubo una notoria presencia de dichos pelotones no degradados, independiente de la región de la raíz en la cual se encontraron.

Para establecer en qué zona de la raíz se encuentran principalmente los hongos micorrízicos, indicados éstos por la presencia de hifas en los cortes histológicos realizados, de 5 plantas de G. araucana, se extrajeron 2 raíces de cada una de ellas. Estos ensayos fueron realizados en un total de 10 raíces, todas ellas recolectadas en la misma época del año. Cada una de las 10 raíces seleccionadas se fragmentaron en 3 porciones: zona basal, intermedia y apical. Se realizaron cortes histológicos de las 3 zonas radicales, observando dichas preparaciones al microscopio óptico con aumento de 100x, para detectar la presencia de hifas y acumulaciones de éstas, considerando como positiva la muestra en la que se observó al menos una hifa fúngica. Mediante cortes superficiales-tangenciales del tejido periférico de la raíz, se extrajeron pelotones de hifas solas, los cuales se llevaron a placas Petri con medio de cultivo fúngico denominado FIM (Brundrett et al., 2001).

\section{RESULTADOS}

Se constató la presencia de pelotones compactos en raíces tomadas al azar de diversos ejemplares de Gavilea araucana. Dichos pelotones compactos se muestran como estructuras globosas bien definidas y nítidas. Bajo el microscopio óptico se distinguen como acumulaciones de hifas, asegurando así que en Orchidaceae, el tejido fúngico forma ovillos dentro de las células radicales.

La mayor cantidad de pelotones se encontraron en otoño. En primavera los pelotones se encontraron digeridos por las células corticales de la raíz.

En cortes transversales de raíz se observó la presencia de hifas a nivel de células parenquimatosas del cilindro cortical, encontrándose estas hifas en los espacios intercelulares o en forma de pelotones dentro de las células parenquimatosas. El mayor porcentaje de colonización micorrízica se encuentra en la región intermedia de las raíces de G. araucana, con un $56 \%$.

Las hifas observadas a nivel de cortes histológicos, muestran ser septadas. Son hifas de diversas longitudes y anchos, lo que se traduce en que quizás, hay presencia de dos clases de micobiontes.

A partir de ovillos de hifas se lograron aislar cultivos puros. El micelio del hongo se desarrolló en aproximadamente 7-8 días, presentándose éste de una coloración parda a un marrón oscuro. Micelio aéreo poco abundante distribuido por toda la colonia. Reverso pardo. El diámetro de la colonia tras cuatro semanas de crecimiento fué de $5 \mathrm{~cm}$. Hifas hialinas a pigmentadas, de diversos diámetros, con presencia o ausencia de fíbulas.

Al menos un tipo de hongo presente en esta asociación pertenece a la Clase Basidiomycota, con presencia de hifas en hebilla. Sin embargo, la presencia de hifas de diversos diámetros de grosor, lleva a pensar que pueden encontrarse dos especies de hongos en los cultivos desarrollados. Con la ayuda de una 
clave de identificación específica para hongos micorrízicos en orquídeas, uno de los hongos presentes en los cultivos podría pertenecer al género Sistotrema. Una determinación específica, sin lugar a dudas, debe asegurarse mediante pruebas moleculares.

\section{CONCLUSIONES}

En Gavilea araucana se constató la presencia de una asociación endomicorrízica, ya que en raíces maduras se observaron hifas septadas a nivel de células corticales.

Los ovillos de hifas, se presentan tanto, en las capas rizodérmicas (estrato epidérmico radical) como, en las células parenquimatosas del cilindro cortical, siempre en ubicación intracelular, como pequeñas estructuras globosas, que según la época del año, se presentan compactas o digeridas, por las células radicales.

Es posible aislar hongos micorrízicos desde pelotones individuales, provenientes de raíces de G. araucana.

\section{REFERENCIAS}

BRUNDRETT, M.; RAMSAY, M.; TAYLOR, R.; DIXON, B.; BATTY,A. 2001. Orchid Conservation Techniques Manual. First International Orchid Conservation Congress. Training course. $113 \mathrm{p}$.

STEUBING, L.; GODOY, R.; ALBERDI, M. 2002. Métodos de Ecología Vegetal. Santiago, Chile, Ed. Universitaria. 345 p.

Agro Sur 35 (2): 69-71 2007

\title{
DIVERSIDAD GENÉTICA DE CULTIVARES DE Lapageria rosea DETERMINADA A TRAVES DE MARCADORES MOLECULARES DEL TIPO ISSR
}

\section{GENETIC DIVERSITY OF Lapageria rosea CULTIVARS DETERMINED BY MOLECULAR ISSR TYPE MARKERS}

\author{
Hoffens, K. y Riegel R. \\ Instituto de Producción y Sanidad Vegetal, Universidad Austral de Chile. \\ Casilla 567, Valdivia, Chile \\ E-mail: karin@hoffens.cl
}

\section{INTRODUCCIÓN}

El copihue es una especie monocotiledónea endémica de Chile perteneciente a la familia Philesiaceae y al género Lapageria, siendo Lapageria rosea la única especie de este género (Martínez, 1985). Lapageria rosea posee un gran potencial ornamental, siendo necesario su mejoramiento y la creación de nuevos cultivares de manera de darle un mayor valor a este material genético nativo, abriendo la posibilidad de registrar y proteger los cultivares obtenidos producto de tal mejoramiento.

El conocimiento de la diversidad genética existente en copihue es una información previa y básica para el establecimiento de programas de mejoramiento genético en esta especie, ya que ésta es necesaria para dirigir el proceso de mejora genética por selección de caracteres (Nuez et al., 2000). Además, el conocimiento de la diversidad genética facilita la identificación de accesiones que permitan conservar la riqueza génica y seleccionar individuos genéticamente distintos para optimizar la heterosis en cruzamientos dirigidos (Qiu et al., 1995).

En Chile se han realizado iniciativas destinadas a establecer programas de mejoramiento genético de copihue y nuevas tecnologías para su producción. Es así como el vivero perteneciente al Instituto Agrícola el Vergel de 